\title{
Impact of Nasal Continuous Positive Airway Pressure Therapy on Markers of Platelet Activation in Patients with Obstructive Sleep Apnea
}

\author{
Morohunfolu E. Akinnusi ${ }^{a} \quad$ Linda L. Paasch $^{a} \quad$ Kristie R. Szarpa ${ }^{a}$ Paul K. Wallace ${ }^{b}$ \\ Ali A. El Solha, c \\ a Division of Pulmonary, Critical Care, and Sleep Medicine, Western New York Respiratory Research Center, \\ Department of Medicine, State University of New York at Buffalo School of Medicine and Biomedical Sciences, \\ ${ }^{b}$ Department of Flow and Image Cytometry, Roswell Park Cancer Institute, and ${ }^{\mathrm{C}}$ Department of Social and \\ Preventive Medicine, State University of New York at Buffalo School of Public Health and Health Professions, \\ Buffalo, N.Y., USA
}

For editorial comment see p. 18

\section{Key Words}

Inflammation · Platelets · Monocytes • Obstructive sleep apnea $\cdot$ Nasal continuous positive airway pressure

\begin{abstract}
Background: Considerable evidence implicates CD40 signaling in the pathogenesis of atheromas. Exposure to CD40 ligand induces platelet-leukocyte conjugation, a heightened expression of inflammatory cytokines, matrix-degrading enzymes, and procoagulant factors. Objectives: To investigate the association between plasma soluble CD40 ligand (sCD40L) and platelet-monocyte aggregates in patients with obstructive sleep apnea (OSA) and to determine whether treatment of OSA with nasal continuous positive airway pressure (nCPAP) alters this relationship. Methods: Twelve patients with OSA who were free of other diseases and 12 healthy controls matched for age, gender, and body mass index had blood drawn for SCD40L and platelet-monocyte aggregate measurements. A repeat assessment was obtained following 8 weeks of nCPAP therapy. Results: Subjects with OSA had significantly higher plasma SCD40L levels and exhibited elevated platelet-monocyte aggregates compared to nonapneic subjects $(7.6 \pm 4.3$ versus $1.7 \pm 1.1$, $p=0.004$; and $41.3 \pm 23.7$ versus $6.7 \pm 4.9, p=0.001$, respec-
\end{abstract}

\section{KARGER}

Fax +41613061234 E-Mail karger@karger.ch www.karger.com
(C) 2008 S. Karger AG, Basel 0025-7931/09/0771-0025\$26.00/0

Accessible online at: www.karger.com/res tively). Both parameters correlated positively with the percentage of time spent with $\mathrm{SpO}_{2}<90 \%(r=0.69, p=0.01$ and $r=0.6, p=0.03$, respectively). After 8 weeks of $n C P A P$ treatment, $s C D 40$ levels declined by $47 \%(p=0.003)$ and plateletmonocyte aggregates by $42 \%(p=0.002)$. None of the controls showed any changes in either SCD40L or plateletmonocyte aggregates after nCPAP therapy. Conclusions: OSA is associated with upregulation of circulating SCD40L levels and platelet-monocyte aggregation that may account for the increased incidence of cardiovascular events in this population. Treatment with nCPAP may alleviate this risk.

Copyright $\odot 2008$ S. Karger AG, Basel

\section{Introduction}

Obstructive sleep apnea (OSA) is a complex disorder characterized by recurrent episodes of upper airway collapse during sleep leading to oxyhemoglobin desaturation and sleep fragmentation. The syndrome has been recognized as a risk factor for hypertension, acute cardiovascular events and metabolic disturbances [1].

Different mechanisms have been advanced to explain the relationship between OSA and cardiovascular disease, including increased sympathetic activity, oxidative

Ali A. El Solh, MD, MPH

Division of Pulmonary, Critical Care, and Sleep Medicine

Erie County Medical Center

462 Grider Street, Buffalo, NY 14215 (USA)

Tel. +1 716898 3375, Fax +1 716898 6139, E-Mail solh@buffalo.edu 
stress, inflammation, and endothelial dysfunction [2-4]. Another purported connection between OSA and cardiovascular disease is enhanced coagulability, possibly mediated by higher levels of circulating apoptotic endothelial cells [5] and platelet activation [6-8]. Indeed, several studies showed that a high percentage of patients with OSA may have a condition of in vivo platelet activation as indicated by increased levels of plasma $\beta$-thromboglobulin, serum thromboxane $\mathrm{B}_{2}$, and soluble P-selectin [8].

Recently our understanding of the interaction between inflammation and OSA has been augmented by the report of increased levels of soluble CD40 ligand (sCD40L) in apneic subjects [9]. CD40L is a transmembrane protein that belongs to the tumor necrosis factor (TNF) family $[10,11]$. It was identified originally on CD4 + T cells but has also been found on mast cells, basophils, eosinophils and activated platelets $[12,13]$. Following expression on the cell surface, CD40L is partly cleaved and released into the circulation as sCD40L, where it binds to $\mathrm{CD} 40$, a receptor constitutively expressed on endothelial cells [14]. The ligand-receptor interaction promotes atherogenesis through platelet aggregation [15], platelet-leukocyte conjugation [16], and generation of reactive oxygen and nitrogen species [17].

In contrast to atherothrombosis, where the role of sCD40L has been systematically investigated $[18,19]$, the association between $\mathrm{SCD} 40 \mathrm{~L}$ and platelet-monocyte aggregates in the biology of OSA remains obscure. Because platelet-monocytes aggregates are known to contribute to ongoing injury at atheromatous sites and in plaque disruption [20], the aims of the study were to investigate the relationship between sCD40L expression and plateletmonocyte aggregates in patients with OSA and to determine whether treatment of OSA with nasal continuous positive airway pressure (nCPAP) alters this relationship.

\section{Methods}

\section{Subjects and Controls}

After receiving approval from the Institutional Review Board at the State University of New York at Buffalo, all consecutive adult patients referred to the Sleep Disorders Clinic at the Erie County Medical Center for suspected OSA between June 2006 and February 2008 were considered for participation in the study provided the following criteria were met: (1) a new diagnosis of OSA by polysomnography; (2) agreement to participate in the investigation by signing an informed consent, and (3) absence of coexisting cardiovascular diseases, diabetes mellitus, renal diseases, or active cigarette smoking. Subjects with a history of neoplastic diseases, or hematologic disorders, or who were regularly using medications were excluded. Control subjects free of comorbidities and sleep-disordered breathing, matched for age, gender, and body mass index (BMI), were enrolled.

\section{Polysomnography}

The diagnosis of OSA was established by standard overnight polysomnography using a computerized recording system (Alice $^{\circledR} 5$ Diagnostic Sleep System; Respironics Inc., Murrysville, Pa., USA). Electroencephalography electrodes were applied at C4-A1, C3-A2, O1-A2, O2-A1. Electrooculography, submental electromyography, appropriate leg and electrocardiography electrodes were applied as previously described. Oxyhemoglobin saturation was recorded by pulse oximetry, respiratory effort by piezoelectric belts, and nasal/oral airflow by pressure sensor. Physiologic signals were digitized (Embla Recording Systems; Medcare, Buffalo, N.Y., USA) for offline analysis of sleep and breathing patterns. Sleep stage scoring was performed on 30-second epochs according to standard criteria [21]. Apnea was defined as complete cessation of airflow for at least $10 \mathrm{~s}$. Hypopnea was defined as any reduction in airflow for more than $10 \mathrm{~s}$ associated with electroencephalographic arousals or $4 \%$ drop in oxygen saturation. The apnea-hypopnea index (AHI) was defined as the total number of apneas and hypopneas per hour of sleep. All sleep scorers had interrater reliability indexes (к) $>0.86$ for staging, arousal, and respiratory parameters. An AHI $\geq 5$ was considered diagnostic of OSA. An AHI $\geq 5$ and $<15$ indicated mild OSA, $\geq 15$ to $<30$ indicated moderate OSA, and $\geq 30$ indicated severe OSA. All patients completed the Epworth Sleepiness Scale (ESS) [22] at their initial visit.

\section{Flow Cytometry}

Peripheral venous blood was drawn from an antecubital vein through a 21-gauge needle into a sodium citrate Vacutainer (Becton Dickinson) after the first $2 \mathrm{ml}$ of blood had been discarded. Samples were immediately fixed for $10 \mathrm{~min}$ with $1.1 \%$ formaldehyde (Polysciences) in $1.4 \times$ Hanks balanced saline solution (Invitrogen), then diluted 4.6 -fold with distilled water to lyse the erythrocytes. Aliquots $(500 \mu \mathrm{l})$ of the fixed/lysed blood samples were concentrated by centrifugation ( $400 \mathrm{~g}$ for $5 \mathrm{~min}$ ), and the resuspended pellet was incubated at $22^{\circ} \mathrm{C}$ for $10 \mathrm{~min}$ with saturating concentrations of the monoclonal antibodies Y2/51-FITC (GPIIIa-specific) and MøP9-PE (CD14-specific). Isotype-matched mouse IgG-FITC (Dako) and preinfusion samples containing no biotinylated platelets served as negative controls. The samples were placed on ice until analysis within $4 \mathrm{~h}$ by flow cytometry (with low-flow setting) on a FACSCalibur flow cytometer (Becton Dickinson) equipped with a 488-nm argon ion and 635-nm diode lasers, standard four-color filter configuration and CELLQuest cell analysis software (Becton Dickinson). A minimum of 2,000 monocytes was counted per test. Using WinList (Werity Software House, Topsham, Me., USA), monocytes were identified and gated by their brightly positive CD14 expression on a two-parameter dot plot displaying linear orthogonal light scatter vs. MøP9-PE (FL2). The threshold was set on forward angle light scatter to include all leukocytes and exclude debris and uncomplexed platelets. The percentage of platelet-monocyte aggregates was identified in single-parameter histograms of Y2/51-FITC (FL1) fluorescence displaying events from the monocyte gate (fig. 1). The positive analysis region was determined using an IgG-FITC conjugated isotypic control. 
Fig. 1. Quantification of platelet activation by whole-blood flow cytometry. Representative histograms from a healthy donor $(\mathbf{a}, \mathbf{b})$ and a patient with OSA (c, d). Monocytes were identified by $(\mathbf{a}, \mathbf{c})$ setting a region (R1) around the brightly CD14positive cells. Platelets were stained with CD61, and the percentage of monocyes positive for CD61 was determined R2 (b, d). a, c Ungated. b, d Gated on R1.

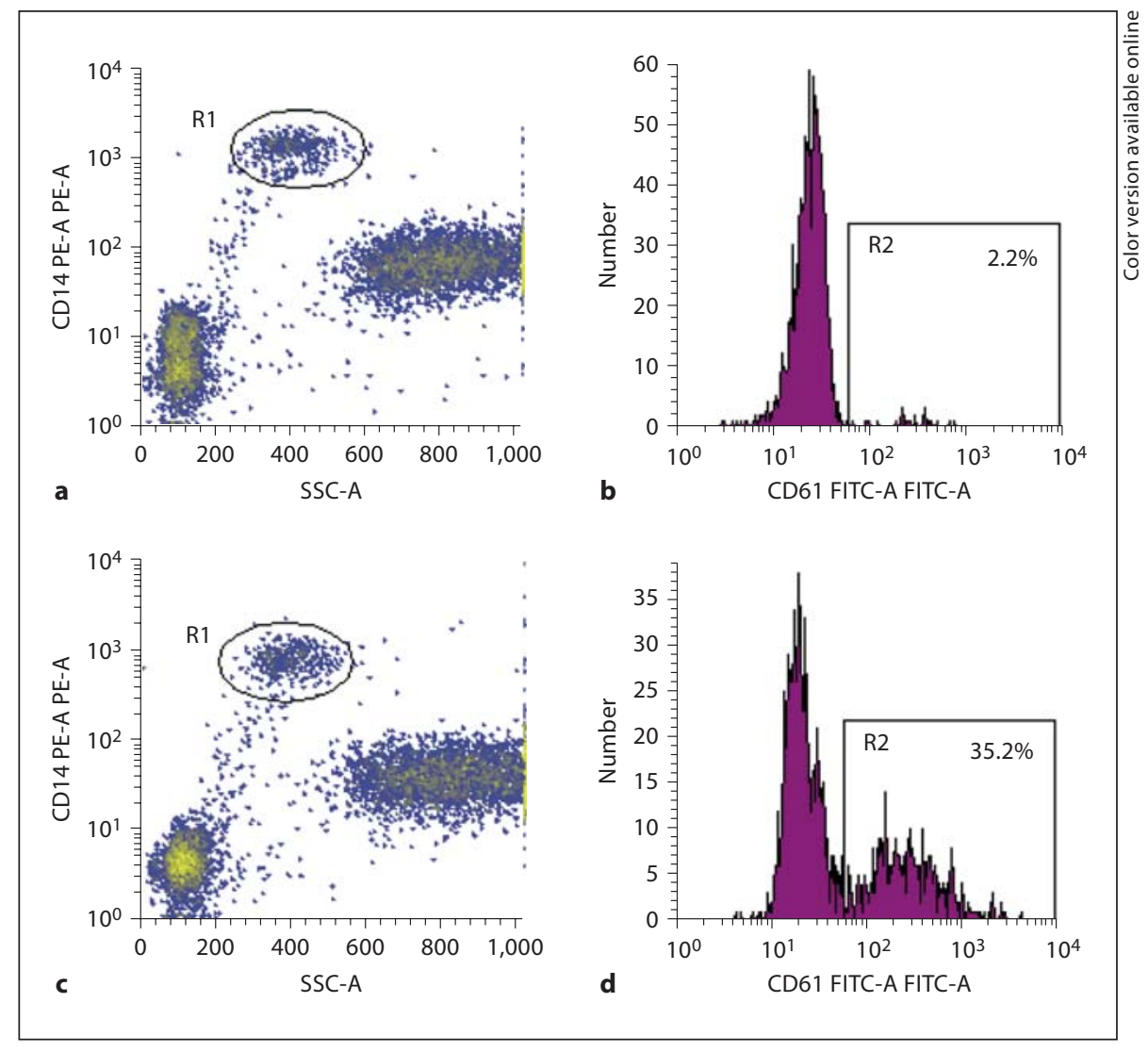

Measurement of Soluble CD40 Ligand Levels

A second venous blood was collected into ethylenediaminetetraacetic acid (EDTA) tubes and centrifuged at $1,500 \mathrm{~g}$ for $15 \mathrm{~min}$ at $4^{\circ} \mathrm{C}$. The platelet-poor plasma component was stored at $-80^{\circ} \mathrm{C}$. Plasma sCD40L levels were detected using a commercially available enzyme-linked immunosorbent assay (ELISA) based on the sandwich principle, according to the manufacturer's instructions (sCD40L ELISA test kit; R\&D Systems, Minneapolis, Minn., USA). The assay is highly specific for the quantitative determination of sCD40L in humans with a detection limit of $0.095 \mathrm{ng} / \mathrm{ml}$ and intra- and interassay coefficients of variation of 6.8 and $14.2 \%$.

\section{nCPAP Therapy}

All patients with OSA were treated with nasal autoCPAP (REMstar; Respironics, Inc.). nCPAP compliance was directly measured using compliance software provided by the manufacturer. Good compliance was defined as nCPAP use for at least $4 \mathrm{~h}$ per night during 5 days of the week with a reduction of obstructive episodes to AHI $<5$ and elimination of snoring. At 8 weeks of nCPAP therapy, samples of venous blood were obtained and processed for flow cytometry and for sCD40L quantitation as previously described.

\section{Sample Size}

Based on a previous study that showed approximately $50 \%$ reduction in sCD40L levels following nCPAP therapy [9], a minimum of 8 pairs of OSA subjects before and after nCPAP therapy was required to achieve a power of 0.8 and an $\alpha$ of 0.05 .

\section{Statistical Analyses}

Data are presented as mean $( \pm S D)$. The distribution of variables was examined by the Kolmogorov-Smirnov Goodness of Fit test. The paired and unpaired Student's t test and Pearson's correlation coefficient were used for normally distributed variables; otherwise, the Wilcoxon-Mann-Whitney U test and Spearman's rank correlation test were applied. Cook's distance was used to assess for potential outliers. All tests performed were two-sided and $\mathrm{p}<0.05$ was considered to indicate statistical significance. Data were analyzed using statistical software (NCSS 2000; Salt Lake City, Utah, USA).

\section{Results}

Twelve patients with polysomnographically confirmed OSA and 12 control subjects were included in the study. Table 1 shows the clinical profile of the study population. Six patients had mild to moderate OSA and 6 patients had severe OSA. There were no significant differences in baseline characteristics between OSA patients and healthy controls. 


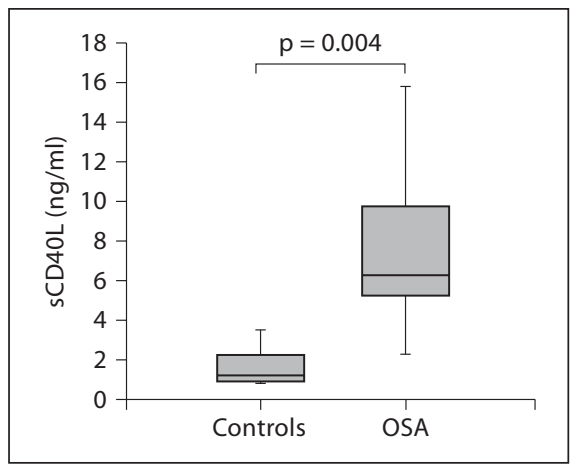

Fig. 2. Comparison of baseline plasma levels of sCD40L in patients with OSA and age-, gender-, and BMI-matched controls.

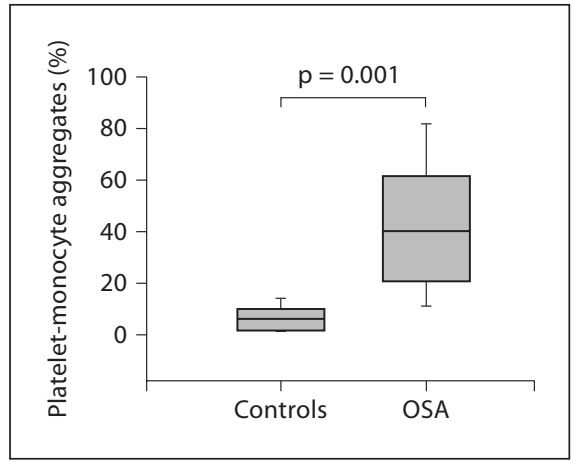

Fig. 3. Comparison of baseline platelet-monocyte aggregates in patients with OSA and age-, gender-, and BMI-matched controls.

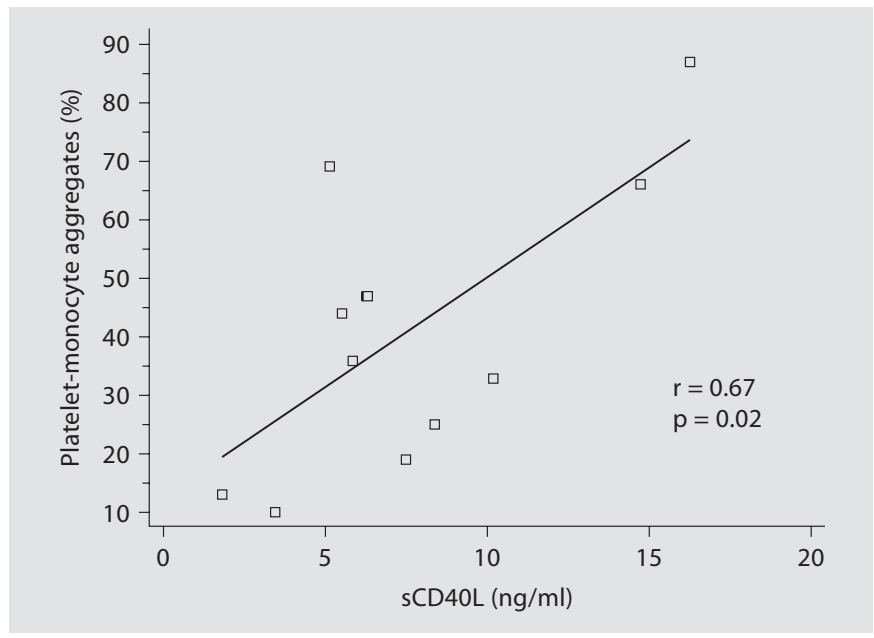

Fig. 4. Correlation between the plasma levels of sCD40L and platelet-monocyte aggregates in patients with OSA.
Table 1. Characteristics of the study population

\begin{tabular}{|c|c|c|c|}
\hline & $\begin{array}{l}\text { OSA } \\
(\mathrm{n}=12)\end{array}$ & $\begin{array}{l}\text { Controls } \\
(\mathrm{n}=12)\end{array}$ & $\begin{array}{l}\mathrm{p} \\
\text { value }\end{array}$ \\
\hline Age, years & $51.9 \pm 14.3$ & $47.8 \pm 7.7$ & 0.33 \\
\hline Gender & $10 / 2$ & $10 / 2$ & 1.0 \\
\hline BMI & $33.9 \pm 4.9$ & $31.7 \pm 3.3$ & 0.28 \\
\hline Systolic blood pressure, $\mathrm{mm} \mathrm{Hg}$ & $125.8 \pm 7.9$ & $121.0 \pm 6.2$ & 0.45 \\
\hline Diastolic blood pressure, $\mathrm{mm} \mathrm{Hg}$ & $74.8 \pm 3.2$ & $71.6 \pm 5.2$ & 0.20 \\
\hline Total cholesterol, mg/dl & $202.7 \pm 21.7$ & $187.9 \pm 16.4$ & 0.15 \\
\hline Blood glucose, mg/dl & $103 \pm 12.4$ & $91.9 \pm 10.8$ & 0.11 \\
\hline \multicolumn{4}{|l|}{ Sleep parameters } \\
\hline ESS & $13.6 \pm 2.3$ & $3.9 \pm 1.7$ & $<0.001$ \\
\hline $\mathrm{AHI}, \mathrm{h}^{-1}$ & $42.1 \pm 31.5$ & $3.7 \pm 1.3$ & $<0.001$ \\
\hline $\mathrm{SpO}_{2}$ nadir, \% & $80.5 \pm 7.2$ & $92 \pm 3.1$ & $<0.001$ \\
\hline Time spent with $\mathrm{SpO}_{2}<90 \%$, min & $37.6 \pm 22.9$ & $0.3 \pm 0.1$ & $<0.001$ \\
\hline Arousal index, $\mathrm{h}^{-1}$ & $52.1 \pm 27.4$ & $1.2 \pm 1.4$ & $<0.001$ \\
\hline
\end{tabular}

Table 2. Correlation coefficients between plasma levels of sCD40L, platelet-monocyte aggregates and ESS, polysomnography variables and metabolic profiles in OSA

\begin{tabular}{lllll}
\hline & sCD40L & p value & MPA & p value \\
\hline Age & 0.13 & 0.68 & 0.07 & 0.83 \\
BMI & 0.07 & 0.81 & 0.42 & 0.16 \\
Cholesterol & 0.47 & 0.12 & 0.32 & 0.31 \\
Glucose & 0.09 & 0.77 & 0.14 & 0.65 \\
ESS & 0.44 & 0.15 & 0.29 & 0.36 \\
AHI & 0.41 & 0.18 & 0.44 & 0.15 \\
Arousal index & 0.35 & 0.26 & 0.39 & 0.22 \\
Percent time with $\mathrm{SpO}_{2}<90 \%$ & 0.69 & 0.01 & 0.64 & 0.03
\end{tabular}

\section{Effect of Sleep Apnea on sCD40L and}

Platelet-Monocyte Aggregates

Plasma SCD40L levels were significantly higher in patients with OSA compared to nonapneic subjects (7.6 \pm 4.3 versus $1.7 \pm 1.1 ; \mathrm{p}=0.004$ ) (fig. 2). Similarly, plateletmonocyte aggregates were increased in subjects who had OSA compared to controls ( $41.3 \pm 23.7$ versus $6.7 \pm 4.9$; $\mathrm{p}=0.001)$ (fig. 3).

Table 2 depicts Spearman's correlation coefficients between plasma levels of sCD40L, platelet-monocyte aggregates and PSG variables, metabolic profile, and ESS in patients with OSA. There were no correlations between sCD40L levels or platelet-monocyte aggregates and age, gender, BMI, severity of OSA, and baseline objective sleepiness. Nor did glucose and total cholesterol show any relationship with either $\mathrm{SCD} 40 \mathrm{~L}$ or platelet-monocyte aggregates. Only the percentage of time spent with $\mathrm{SpO}_{2}$

Akinnusi/Paasch/Szarpa/Wallace/ El Solh 
Fig. 5. Effect of 8 weeks nCPAP therapy on plasma levels of SCD40L (a) and plateletmonocyte aggregates (b) in patients with OSA.

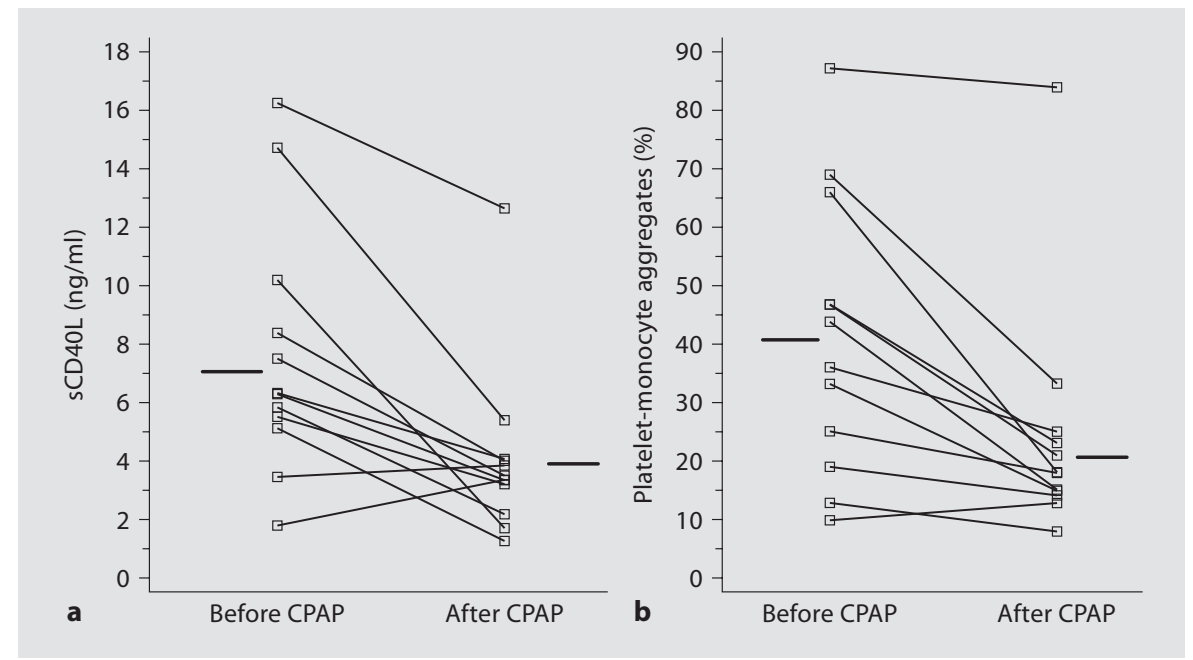

$<90 \%$ correlated positively with plasma sCD40L levels $(\mathrm{r}=0.69 ; \mathrm{p}=0.01)$ and platelet-monocyte aggregates $(\mathrm{r}=$ $0.64 ; \mathrm{p}=0.03)$, respectively. Moreover, levels of $\mathrm{sCD} 40 \mathrm{~L}$ displayed a significant correlation with platelet-monocyte aggregates $(\mathrm{r}=0.67, \mathrm{p}=0.02)$ (fig. 4 ).

\section{Treatment Effect on sCD40L and Platelet-Monocyte Aggregates}

The average pressure setting for the nCPAP device was $8.4 \pm 1.7 \mathrm{~mm} \mathrm{Hg}$ (range 7-14). The use of nCPAP ranged from 4 to $7 \mathrm{~h}$ per night with an average of $5.3 \pm 1.1 \mathrm{~h}$ per night. After 8 weeks of autoCPAP therapy, there was no significant change in anthropometric and metabolic profile compared to baseline (table 3). ESS and AHI were reduced to $3.8 \pm 1.4$ and $2.3 \pm 0.7$ per hour, respectively, on successful nCPAP ( $\mathrm{p}<0.001)$. The percentage of time spent with $\mathrm{SpO}_{2}<90 \%$ also decreased to $2.6 \pm 2.3(\mathrm{p}<$ 0.001 ). When compared to the data obtained before nCPAP initiation, sCD40L was reduced by $47 \%$ (to $4.0 \pm$ $2.9 \mathrm{ng} / \mathrm{ml}, \mathrm{p}=0.003)$ and platelet-monocyte aggregates by $42 \%$ (to $23.9 \pm 20.1 \%, p=0.002$ ) (fig. 5). In 7 control subjects without sleep apnea, the use of nasal autoCPAP did not alter the plasma levels of sCD40L or the plateletmonocyte aggregates.

\section{Discussion}

In the current study, we have demonstrated that increased plasma sCD40L expression occurs in tandem with in vivo platelet activation among subjects with OSA. These derangements were correlated with hypoxic stress.
Table 3. Anthropometric and metabolic profile for OSA patients at baseline and after nCPAP therapy

\begin{tabular}{lcc}
\hline & $\begin{array}{c}\text { Baseline } \\
(\mathrm{n}=12)\end{array}$ & $\begin{array}{c}\text { Following } \\
\text { CPAP }(\mathrm{n}=12)\end{array}$ \\
\hline BMI & $33.9 \pm 4.9$ & $33.7 \pm 5.0$ \\
Systolic blood pressure, mm Hg & $125.8 \pm 7.9$ & $124.6 \pm 7.3$ \\
Diastolic blood pressure, mm Hg & $74.8 \pm 3.2$ & $72.3 \pm 3.5$ \\
Total cholesterol, mg/dl & $202.7 \pm 21.7$ & $198.1 \pm 19.8$ \\
Glucose, mg/dl & $103 \pm 12.4$ & $97 \pm 13.1$ \\
\hline
\end{tabular}

The 8-week treatment with nCPAP reduced, but failed to normalize, plasma levels of SCD40L and platelet-monocyte aggregates.

Recent interest has focused on the measurement of sCD40L for risk stratification of patients with coronary artery disease or at risk of developing coronary artery disease. Pilot studies have found that individuals with hypercholesterolemia [23] and diabetes [24] have elevated sCD40L levels and that very high levels of sCD40L may identify apparently healthy women at increased risk of having a first adverse cardiovascular event [25]. While a causal relationship is still lacking, the findings of the current study provide further evidence of the association between OSA and cardiovascular diseases by demonstrating higher levels of sCD40L in apneic patients than in healthy controls. The elevated sCD40L levels correlated positively with platelet-monocyte aggregates and were directly related to hypoxic stress in these patients. Similar observations were reported in two recent clinical investi- 
gations $[9,26]$. In a prospective study involving 35 apneic patients and 16 control subjects, Kobayashi et al. [9] showed that baseline sCD40L was significantly higher in patients with severe OSA and that SCD40L levels correlated with the amount of time spent at $<90 \%$ oxygen saturation. Similarly, Minogushi et al. [26] reported a comparable association between $\mathrm{SCD} 40 \mathrm{~L}$ and hypoxic stress when evaluating OSA patients with silent brain infarct. Taken together, these data suggest that hypoxia may mediate platelet activation. Whether this reaction occurs as a result of increased activation of the sympathetic pathway [27] or as a direct effect of chronic intermittent hypoxia [28], evidence suggests that upon platelet activation, CD40L becomes expressed on the platelet surface which is then cleaved over a period of minutes to hours, generating the soluble fragment sCD40L [29]. Upon binding to CD40, several inflammatory processes are initiated, including the expression of cytokines, chemokines, growth factors and adhesion molecules $[30,31]$ that are integral components to the progression of atheromas.

The positive correlation between $\mathrm{SCD} 40 \mathrm{~L}$ and plateletmonocyte aggregates in our analysis provides further evidence for the role of sCD40L in the pathogenesis of atherothrombotic disease in subjects with sleep apnea. Sustained release of platelet sCD40L $[32,33]$ has been implicated in the formation of platelet-monocyte aggregates via P-selectin [34], which can trigger monocyte arrest to inflamed endothelium via the conveyance of RANTES by platelets [35]. Platelet-activated monocytes can then initiate the extrinsic pathway of coagulation via surface expression of tissue factor while facilitating adhesion to the endothelium via expression of the $\beta 2$-integrin Mac- 1 $[36,37]$. The clinical relevance of this interaction was shown by Furman et al. [38], who demonstrated elevated levels of platelets attached to monocytes in patients with acute coronary artery disease. These findings are supported also by the fact that inhibition of P-selectin interrupted platelet interactions with monocytes and reduced the formation of atherosclerotic lesions in apoliproteinE-deficient mice [39].

Consistent with previous studies $[9,26]$, correction of nocturnal hypoxemia with nCPAP therapy resulted in a reduction in the levels of sCD40L and platelet-monocyte aggregates. However, the mean plasma sCD40L levels following nCPAP therapy did not match those of healthy controls at baseline. Although the sleep indices have improved compared to pre-nCPAP levels, persistent hypoxic events expressed as percent time spent at $<90 \%$ oxygen saturation were noted in few cases, which could have contributed to higher SCD40L than in normal controls. It is plausible also that the 8-week therapy with nCPAP might be too short to restore normal SCD40L levels in these patients. Alternatively, the higher residual sCD40L levels among subjects with OSA may indicate the presence of an additional sleep-related signal activation of CD40 independent of hypoxic stress. We should point out that platelet-poor EDTA plasma was used for measurement of in vivo $\mathrm{SCD} 40 \mathrm{~L}$ in our patients. Sample-processing methods can profoundly affect measured levels of sCD40L, with serum yielding levels 3 - to 5 -fold higher than plasma [40]. Moreover, platelet count influences serum levels of sCD40L, a confounding factor avoided by use of plateletpoor plasma in the present study. Finally, EDTA inhibits the release of CD40L from the platelet surface when administered before platelet activation $[41,42]$, thus preventing ex vivo release of sCD40L.

A major limitation of the present study is that the effects of nCPAP on plasma SCD40L levels and plateletmonocyte aggregates were not examined with a randomized, placebo-controlled design because of the difficulties of placebo nCPAP treatment. Second, because this is an observational study, we could not establish a causal relationship between OSA and increased levels of plateletmonocyte aggregates or sCD40L. We have attempted, however, to minimize confounding variables by matching the groups for age, gender and BMI.

In conclusion, we have demonstrated increased plasma sCD40L levels with a concomitant rise in platelet-monocyte aggregates in OSA patients. These findings provide insight into the mechanisms by which sCD40L may contribute to atherothrombotic events in this population. Treatment with nCPAP may help to alleviate this risk.

References

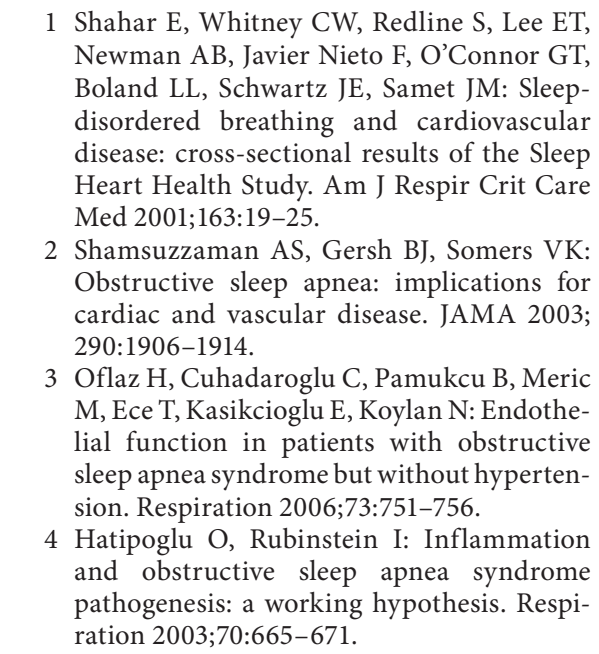

Akinnusi/Paasch/Szarpa/Wallace/ El Solh 
$\checkmark 5$ El Solh AA, Akinnusi ME, Baddoura FH, Mankowski CR: Endothelial cell apoptosis in obstructive sleep apnea: a link to endothelial dysfunction. Am J Respir Crit Care Med 2007;175:1186-1191

6 Bokinsky G, Miller M, Ault K, Husband P, Mitchell J: Spontaneous platelet activation and aggregation during obstructive sleep apnea and its response to therapy with nasal continuous positive airway pressure. A preliminary investigation. Chest 1995;108:625630.

7 Eisensehr I, Ehrenberg BL, Noachtar S, Korbett K, Byrne A, McAuley A, Palabrica T: Platelet activation, epinephrine, and blood pressure in obstructive sleep apnea syndrome. Neurology 1998;51:188-195.

-8 Geiser T, Buck F, Meyer BJ, Bassetti C, Haeberli A, Gugger M: In vivo platelet activation is increased during sleep in patients with obstructive sleep apnea syndrome. Respiration 2002;69:229-234.

-9 Kobayashi K, Nishimura Y, Shimada T, Yoshimura S, Funada Y, Satouchi M, Yokoyama $\mathrm{M}$ : Effect of continuous positive airway pressure on soluble CD40 ligand in patients with obstructive sleep apnea syndrome. Chest 2006;129:632-637.

-10 Smith CA, Farrah T, Goodwin RG: The TNF receptor superfamily of cellular and viral proteins: activation, co-stimulation, and death. Cell 1994;76:959-962.

-11 Banchereau J, Bazan F, Blanchard D, Brière F, Galizzi JP, van Kooten C, Liu YJ, Rousset F, Saeland S: The CD40 antigen and its ligand. Annu Rev Immunol 1994;12:881-922.

-12 Aukrust P, Wæhre T, Damås JK, Gullestad L, Solum NO: Inflammatory role of platelets in acute coronary syndromes. Heart 2001;86: 605-606.

13 Anand SX, Viles-Gonzalez JF, Badimon JJ, Cavusoglu E, Marmur JD: Membrane-associated CD40L and SCD40L in atherothrombotic disease. Thromb Haemost 2003;90: 377-384.

14 Van Kooten C, Banchereau J: CD40-CD40 ligand: a multifunctional receptor-ligand pair. Adv Immunol 1996;61:1-77.

$\checkmark 15$ Inwald DP, McDowall A, Peters MJ, Callard RE, Klein NJ: CD40 is constitutively expressed on platelets and provides a novel mechanism for platelet activation. Circ Res 2003;92:1041-1048.

-16 Harding SA, Sarma J, Josephs DH, Cruden NL, Din JN, Twomey PJ, Fox KA, Newby DE: Upregulation of the CD40/CD40 ligand dyad and platelet-monocyte aggregation in cigarette smokers. Circulation 2004;109: 1926-1929.

-17 Chakrabarti S, Varghese S, Vitseva O, Tanriverdi K, Freedman JE: CD40 ligand influences platelet release of reactive oxygen intermediates. Arterioscler Thromb Vasc Biol 2005;25:2428-2434.
8 Schönbeck U, Sukhova GK., Shimizu K, Mach F, Libby P: Inhibition of CD40 signaling limits evolution of established atherosclerosis in mice. Proc Natl Acad Sci USA 2000;97:7458-7463.

19 Cipollone F, Mezzetti A, Porreca E, Di Febbo C, Nutini M, Fazia M, Falco A, Cuccurullo F, Davì G: Association between enhanced soluble CD40L and prothrombotic state in hypercholesterolemia: effects of statin therapy. Circulation 2002;106:399-402.

20 van der Wal AC, Becker AE: Atherosclerotic plaque rupture - pathologic basis of plaque stability and instability. Cardiovasc Res 1999;41:334-344.

21 Rechtschaffen A, Kales A (eds): A Manual of Standardized Terminology, Technique, and Scoring System for Sleep Stages of Human Subjects. Los Angeles, BIS/BRI, UCLA, 1968.

22 Johns MW: A new method for measuring daytime sleepiness: the Epworth sleepiness scale. Sleep 1991;14:540-545.

23 Garlichs CD, John S, Schmeisser A, Eskafi S, Stumpf C, Karl M, Goppelt-Struebe M, Schmieder R, Daniel WG: Upregulation of CD40 and CD40 ligand (CD154) in patients with moderate hypercholesterolemia. Circulation 2001;104:2395-2400.

24 Varo N, Vicent D, Libby P, Nuzzo R, CallePascual AL, Bernal MR, Fernández-Cruz A, Veves A, Jarolim P, Varo JJ, Goldfine A, Horton E, Schönbeck U: Elevated plasma levels of the atherogenic mediator soluble CD40 ligand in diabetic patients: a novel target of thiazolidinediones. Circulation 2003; 107: 2664-2669.

25 Schönbeck U, Varo N, Libby P, Buring J, Ridker PM: Soluble CD40L and cardiovascular risk in women. Circulation 2001;104:22662268.

26 Minoguchi K, Yokoe T, Tazaki T, Minoguchi H, Oda N, Tanaka A, Yamamoto M, Ohta S, O'Donnell CP, Adachi M: Silent brain infarction and platelet activation in obstructive sleep apnea. Am J Respir Crit Care Med 2007;175:612-617.

27 Jennum P, Wildschiødtz G, Christensen NJ, Schwartz T: Blood pressure, catecholamines, and pancreatic polypeptide in obstructive sleep apnea with and without nasal Continuous Positive Airway Pressure (nCPAP) treatment. Am J Hypertens 1989;2:847-852.

28 Dunleavy M, Dooley M, Cox D, Bradford A: Chronic intermittent asphyxia increases platelet reactivity in rats. Exp Physiol 2005; 90:411-416.

29 André P, Nannizzi-Alaimo L, Prasad SK, Phillips DR: Platelet-derived CD40L: the switch-hitting player of cardiovascular disease. Circulation 2002;106:896-899.

30 Kotowicz K, Dixon GL, Klein NJ, Peters MJ, Callard RE: Biological function of CD40 on human endothelial cells: costimulation with CD40 ligand and interleukin-4 selectively induces expression of vascular cell adhesion molecule-1 and P-selectin resulting in preferential adhesion of lymphocytes. Immunology 2000;100:441-448.
31 Henn V, Slupsky JR, Gräfe M, Anagnostopoulos I, Förster R, Müller-Berghaus G, Kroszek RA: CD40 ligand on activated platelets triggers an inflammatory reaction of endothelial cells. Nature 1998;391:591-594.

32 Viallard JF, Solanilla A, Gauthier B, Contin C, Déchanet J, Grosset C, Moreau JF, Praloran V, Nurden P, Pellegrin JL, Nurden AT, Ripoche J: Increased soluble and plateletassociated CD40 ligand in essential thrombocythemia and reactive thrombocytosis. Blood 2002;99:2612-2614.

-33 Jin Y, Nonoyama S, Morio T, Imai K, Ochs HD, Mizutani S: Characterization of soluble CD40 ligand released from human activated platelets. J Med Dent Sci 2001;48:23-27.

-34 Sarma J, Laan C, Alam S, Jha A, Fox KA, Dransfield I: Increased platelet binding to circulating monocytes in acute coronary syndromes. Circulation 2002;105:2166-2171.

$\checkmark 35$ von Hundelshausen P, Weber KS, Huo Y, Proudfoot AE, Nelson PJ, Ley K, Weber C: RANTES deposition by platelets triggers monocyte arrest on inflamed and atherosclerotic endothelium. Circulation 2001;103: 1772-1777.

-36 Altieri DC, Morrissey JH, Edgington TS: Adhesive receptor Mac-1 coordinates the activation of factor $\mathrm{X}$ on stimulated cells of monocytic and myeloid differentiation: an alternative initiation of the coagulation protease cascade. Proc Natl Acad Sci USA 1988; 85:7462-7466.

37 Zillmann A, Luther T, Müller I, Kotzsch M, Spannagl M, Kauke T, Oelschlägel U, Zahler S, Engelmann B: Platelet-associated tissue factor contributes to the collagen-triggered activation of blood coagulation. Biochem Biophys Res Commun 2001;281:603-609.

-38 Furman MI, Barnard MR, Krueger LA, Fox ML, Shilale EA, Lessard DM, Marchese P, Frelinger AL 3rd, Goldberg RJ, Michelson AD: Circulating monocyte-platelet aggregates are an early marker of acute myocardial infarction. J Am Coll Cardiol 2001;38: 1002-1006.

39 Huo Y, Schober A, Forlow SB, Smith DF, Hyman MC, Jung S, Littman DR, Weber C, Ley $\mathrm{K}$ : Circulating activated platelets exacerbate atherosclerosis in mice deficient in apolipoprotein E. Nat Med 2003;9:61-67.

$>40$ Ahn ER, Lander G, Jy W, Bidot CJ, Jimenez JJ, Horstman LL, Ahn YS: Differences of soluble CD40L in sera and plasma: implications on CD40L assay as a marker of thrombotic risk. Thromb Res 2004;114:143-148.

41 Nannizzi-Alaimo L, Rubenstein MH, Alves VL, Leong GY, Phillips DR, Gold HK: Cardiopulmonary bypass induces release of soluble CD40 ligand. Circulation 2002;105: 2849-2854.

42 Furman MI, Krueger LA, Linden MD, Barnard MR, Frelinger AL 3rd, Michelson AD: Release of soluble CD40L from platelets is regulated by glycoprotein IIb/IIIa and actin polymerization. J Am Coll Cardiol 2004;43: 2319-2325. 